Jeffrey Stackert

\title{
Rewriting the Torah
}

\section{Literary Revision in Deuteronomy and the Holiness Legislation}

[Das Fortschreiben der Tora. Die literarische Revision des Deuteronomiums und das Heiligkeitsgesetz.]

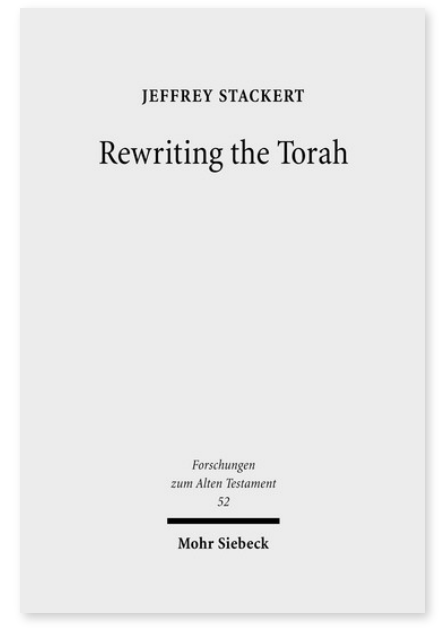

2007. XI, 273 Seiten. FAT 52

ISBN 978-3-16-151093-9

DOI 10.1628/978-3-16-151093-9

eBook PDF 109,00€

ISBN 978-3-16-149298-3

Leinen $109,00 €$
Veröffentlicht auf Englisch.

Jeffrey Stackert untersucht literarische Parallelen innerhalb der Gesetzestexte des Pentateuch und vor allem die Beziehungen zwischen ähnlichen Gesetzen im Deuteronomium und dem Heiligkeitsgesetz (Lev 17-26). Seine Analyse bestimmter Gesetze im Pentateuch führt inn zu der These, daß das Heiligkeitsgesetz sowohl vom Bundesbuch als auch vom Deuteronomium abhängt. Er erläutert die Arbeitsweise der Verfasser des Heiligkeitsgesetzes und zeigt, daß sie eine Art literarischer Revision anwenden und ihre Quellen so ihren eigenen ideologischen Vorstellungen anpassen. Das Heiligkeitsgesetz zeigt sich also als ein 'Supergesetz', das die inm vorausgehenden priesterlichen und nicht-priesterlichen Gesetze sammelt und neu aufbereitet.

Jeffrey Stackert Born 1977; Ph.D. in Near Eastern and Judaic Studies from Brandeis University (Waltham, Massachusetts); currently Assistant Professor of Hebrew Bible at the University of Minnesota.
Jetzt bestellen:
https://mohrsiebeck.com/buch/rewriting-the-torah-9783161510939?no_cache=1
order@mohrsiebeck.com
Telefon: +49 (0)7071-923-17
Telefax: +49 (0)7071-51104 